\title{
The use of panoramic radiographs modified by an open access software to determine Mandibular Cortical Index
}

\author{
Luciana Munhoz ${ }^{\mathrm{a}}$, Claudia Fabiana Joca de Arruda $^{\mathrm{a}}$, Fernando Amorim Mendonça Alves ${ }^{\mathrm{a}}$, Emiko Saito Arita ${ }^{\mathrm{a}}$, \\ Silvia Vanessa Lourenço ${ }^{a}$, Claudio Costa ${ }^{a}$
}

\begin{abstract}
OBJECTIVE: To compare assessment of panoramic radiographs using Mandibular Cortical Index $(\mathrm{MCl})$ by a radiologist with experience and two dentists with no experience in this index using original radiograph images and inverted images.

METHODS: 64 panoramic radiographs were analyzed by three observers: a radiologist with previous experience in $\mathrm{MCl}$ and two trained dentists with no previous experience. First, the original images were assessed by the radiologist and defined as the gold standard. Then, dentists received training in the $\mathrm{MCl}$. Assessment results obtained from the three observers were analyzed.

RESULTS: When compared results from the experienced radiologist to positive and inverted images, no statistical significant difference was found. When considering the two trained observers, we found that inverted images had a lower agreement between the gold standard original images.

CONCLUSION: We concluded that, within the limitations of this study, inverted radiographs are not recommended for $\mathrm{MCl}$ assessment.
\end{abstract}

Key words: Osteoporosis; Panoramic radiography; Dental digital radiography; Software tools

\section{O uso de radiografias panorâmicas modificadas por um software de acesso gratuito na determinação do Índice da Cortical Mandibular}

\section{RESUMO}

OBJETIVO: Comparar a avaliação de radiografias panorâmicas usando o Índice Cortical Mandibular (ICM) por um radiologista com experiência e dois cirurgiões dentistas sem experiência neste índice usando imagens de radiografia originais e imagens invertidas.

METODOLOGIA: 64 radiografias panorâmicas foram analisadas por três observadores: um radiologista com experiência prévia com o ICM e dois dentistas treinados sem experiência prévia. Inicialmente, as imagens originais foram avaliadas pelo radiologista e definidas como padrão-ouro. Então, os dentistas receberam treinamento para aplicar o ICM. Os resultados da avaliação obtidos dos três observadores foram analisados. RESULTADOS: Qquando comparados os resultados do radiologista experiente em imagens positivas e invertidas, não foi encontrada diferença estatística significante. Ao considerar os dois observadores treinados, descobrimos que as imagens invertidas apresentaram menor concordância com o padrão ouro.

CONCLUSÃO: Concluímos que, dentro das limitações deste estudo, as radiografias invertidas não são recomendadas para a avaliação do ICM.

Palavras-chave: Osteoporose; Radiografia panorâmica; Radiografia dentária; Software a Department of Stomatology, School of Dentistry, University of São Paulo, São Paulo, Brazil

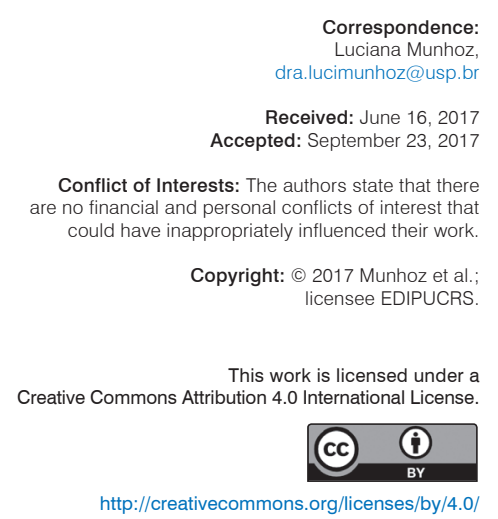

http://creativecommons.org/licenses/by/4.0/ 


\section{INTRODUCTION}

Systemic osteoporosis is a multi-cause metabolic bone disease characterized by progressive degenerative changes in bone microarchitecture, resulting in a higher fracture risk [1,2]. Osteoporotic fractures are a considerable burden worldwide and lead to higher risk of subsequent fractures [3]. The prevalence of osteoporosis is predicted to rise dramatically with the increase in elderly population [4]; as well as the mortality risk after an osteoporotic fracture [5].

The gold standard method for diagnosing osteoporosis is dual energy X-ray absorptiometry (DXA), which measures bone mineral density (BMD) [6]; however access to DXA is not widely available in many countries [7]. Thus, a significant number of patients with established osteoporosis are underdiagnosed [8], and, consequently, not treated, despite the availability of effective treatments $[9,10]$.

In contrast, panoramic radiographs are frequently used in dentistry routine practice $[4,11]$ to investigate and diagnose dentomaxilofacial pathologies [12-14]; and it is a low cost easy access radiographic technique. Many researchers advocate its use for screening for osteoporosis [4, $8,15-24]$ by the fact that the mandibular cortical bone may reflect changes in bone architecture of other sites from skeleton $[4,12,15]$.

In panoramic radiography, porosity in the basal cortex of the mandibular body can be assessed using Mandibular Cortical index (MCI) [12]. According to previous reports, $\mathrm{MCI}$ is useful for screening patients at risk of osteoporosis and it is inversely correlated with $\operatorname{BMD}[16,25,26]$. MCI also has moderate diagnostic accuracy $[12,16]$. Notwithstanding, MCI is a subjective visual index of easy application; does not require specific software or instruments and can be widely used by properly trained dentists.

Due to the importance of panoramic radiography to screening patients at risk of osteoporosis, as well as the MCI index, the objective of this study was to compare assessment of panoramic radiographs using Mandibular Cortex Index (MCI) by different observers. Furthermore, we evaluated the results assessed from the original (positive) and modified (inverted) radiographic images to confirm the influence of inverted radiographic images in MCI classification results.

\section{METHODS}

\section{Panoramic Radiographs Selection}

This research was conducted using 64 panoramic radiographs selected by a radiologist with experience in MCI from the archives of the Oral Radiology Department. The sample was created with radiographs previously classified by the expert according to the MCI and it included radiographs with all three MCI categories. Approval was obtained from the university ethics committee (number 30821814.0.0000.0075). The guidelines of Helsinki were followed in this investigation.

\section{Inclusion and exclusion criteria}

The panoramic radiographs were performed by the same device (Kodak 8000, Eastman Kodak Company, Rochester,
United States of America). Radiographs with technical failures were not included in the sample as well as the ones with lesions or alterations in the area of interest or adjacencies. All images were processed through the same software (ImageJ, National Institute of Health, Bethesda, MD, USA).

\section{Mandibular Cortical Index}

The MCI was assessed by evaluating the appearance of the cortical bone below the mandibular foramen, using Klemetti et al (1994) [25] classification. The inferior mandibular cortex was classified as follows: $\mathrm{C} 1=$ normal, when presenting marked endosteal margin; $\mathrm{C} 2=$ moderately eroded, when presenting evidence of lacunar resorption or endosteal cortical residues; and C3 = severely eroded, when clear porosity or linear lacunae marks were observed. In Figure 1, a schematic drawing of the classification used, based on Klemetti index.

All panoramic radiomorphometric measurements were performed in a random order by a radiologist with experience in using MCI and two trained dentists with no previous experience in MCI evaluation: one was a postgraduate student in oral radiology (\#1) and the second was a post-graduate student in oral pathology $(\# 2)$. Inter and intraobserver reliability was assessed between measurements performed one week apart to eliminate memory bias. At the first moment of the evaluation, the observers classified the radiographs using the original images (positive) and then the modified images (inverted); but always in different days and with a three-day interval minimum. Both sides of panoramic radiographs were assessed and recorded separately for further statistical analysis. An example of a panoramic used in this study in original and inverted is demonstrated (Figure 2).

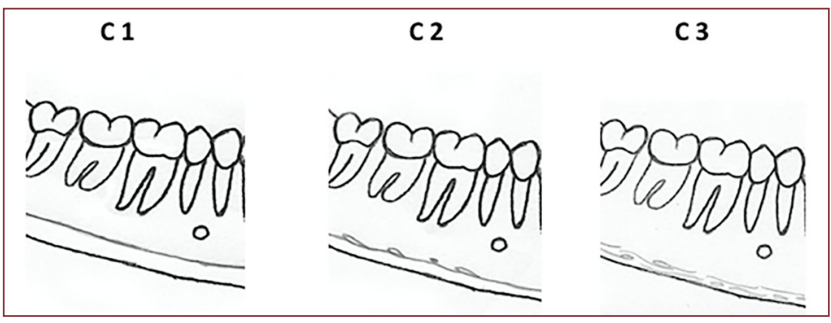

Figura 1. Schematic drawing of the classification used, based on Klemetti index (25).
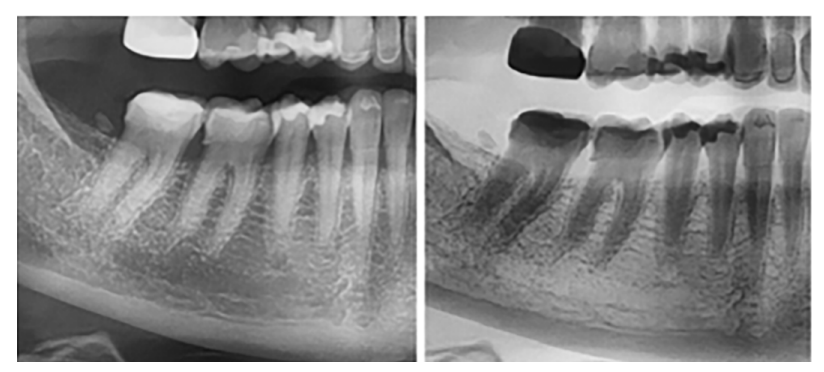

Figure 2. An example of an original and inverted panoramic image used in this study. 
The original images that were assessed by the experienced radiologist were defined as the gold standard. Comparisons between the experienced radiologist assessment with the positive and with the negative images were performed as well as comparisons between the observers \#1 and \#2.

\section{Statistical Analysis}

Intra and interobserver agreement were assessed using the Kappa test for MCI. Normality was assessed for variables using the Lilliefors test. Differences in MCI evaluations were analyzed using the Kruskal Wallis test, with the appropriate post-hoc. All statistical assessment were performed at a level of significance of 5\% (IBM SPSS Statistics 17, SPSS Inc. Chicago, IL).

The statistical analysis of the radiographs MCI was performed in two stages. First, the analysis was done by the experienced radiologist. Second, the experienced radiologist results were compared with others.

\section{RESULTS}

A total of 384 MCI classifications (192 in positive images and 192 in inverted images) were assessed by the three observers in 96 panoramic radiographs. Intraobserver reproducibility (kappa $=0.82,95 \% \mathrm{CI}=0.79-0.90, p=0.01$ ) and interobserver reliability were confirmed for MCI categorical measurements (kappa $=0.80,95 \%$ CI $=0.75$ $0.88, p=0.01$ ), using a subsample of 10 panoramic images in original.

When comparing results from the experienced radiologist for positive and inverted images, we found no statistical significant difference between the analysis of positive and inverted images in different days, according to KruskalWallis test $(p=0.8829)$.

The results of the second stage, when considering the three observers and all the radiographs assessed in positive and inverted are described in Table $\mathbf{1 .}$

Table 1. Comparison between the experienced radiologist and the trained dentists number \#1 and \#2; according to kappa test.

\begin{tabular}{|c|c|c|}
\hline Observer & Positive images & Inverted images \\
\hline $\begin{array}{l}\mathrm{MCl} \text { previous experienced } \\
\text { Radiologist }\end{array}$ & Gold standard ${ }^{A}$ & $0.79^{A B}$ \\
\hline Trained dentist \#1 & $0.81^{\mathrm{A}}$ & $0.71^{\mathrm{B}}$ \\
\hline Trained dentist \#2 & $0.71^{A}$ & $0.41^{\mathrm{C}}$ \\
\hline
\end{tabular}

Same letters indicate no difference between groups for $\mathrm{MCl}$ results according to KruskalWallis test and Dunn post hoc when $p<0.05$.

\section{DISCUSSION}

Due to its low cost, panoramic radiography is frequently used in diagnostic hypothesis in head and neck regions [27-29]. Currently, panoramic radiography is also useful in osteoporosis risk assessment $[4,8,15,18-20,22,24,30]$.
The use of radiomorphometric indices, such as MCI, and their correlation with low BMD were extensively studied by many researchers $[15,16,18-21,25,31]$. The MCI index can be easily applied by dentists who have received proper training [32,33].

Digital radiography offers the possibility of manipulating images, these modifications through image filters can alter the initial appearance of the radiography [34].

Our study aimed to compare the MCI evaluation in digital panoramic radiographs performed by a radiologist with previous experience in MCI and two non-experienced dentists who received training in the use of this index. The non-experienced dentists received training only with positive images. We analyzed if inverted images could be able to increase the accuracy of MCI assessment for nonexperienced dentists, when compared to the experienced radiologist. To our acknowledgment, this is the first study using inverted images to assess MCI in panoramic radiographs.

The results showed that the two non-specialists were able to perform MCI assessment by original images, after proper training, with similar results than the experienced radiologist. However, when the images were modified (inverted), there was information loss between the three dentists, specially to the oral pathologist (\#2). The results presented by the experienced radiologist were different from the gold standard evaluation, but not statistically significant $(p<0.05)$.

In studies using manipulated images It has been observed that dentists with less experience in digital radiography may present loss of information when using manipulated digital images; however, specialists can obtain extra information from the digital radiographs [35]. Some studies have used image changing (such as the inverted image) to obtain additional information to perform diagnosis $[36,37]$. In the first study found in literature (1993), three different imaging filters were applied in the diagnostic of distinct dental diseases. It was observed that dentists preferred to perform the diagnosis assessment in modified images rather than in the original images [38]. Further study have recommended the use of modified images to compare cysts and tumors [39].

Several studies applied modified images for distinct purposes. It was observed that the use of the inverted images may be beneficial for the detection of root canals [40], and it can be useful for detecting health disorders in medical fields [36,37]. For cephalometric measurements, no advantage was noticed, the two images presented the same level of accuracy [41]. For proximal carious lesions, the image inversion did not present any benefits [42].

In the present study, inverted images provided no benefits to $\mathrm{MCI}$ assessment in panoramic radiographs; based on our results we don't recommend its use for MCI determination. Same recommendation was made by other researchers for different applications $[42,43]$.

The limitations of this study were the small number of observers and the small number of images evaluated. 


\section{CONCLUSIONS}

We concluded that image inversion is not recommended for osteoporotic risk assessment by MCI. The less experienced observer (oral pathologist) showed poor concordance when compared to experienced observers (oral radiologists).

\section{REFERENCES}

1. Lippuner $\mathrm{K}$. The future of osteoporosis treatment - a research update Swiss Med Wkly. 2012;142:w13624. https://doi.org/10.4414/smw.2012. 13624

2. Calciolari E, Donos N, Park JC, Petrie A, Mardas N. Panoramic measures for oral bone mass in detecting osteoporosis: a systematic review and meta-analysis. J Dent Res. 2015;94(3 Suppl):17S-27S. https://doi. org/10.1177/0022034514554949

3. Nojiri S, Burge RT, Flynn JA, Foster SA, Sowa H. Osteoporosis and treatments in Japan: management for preventing subsequent fractures. J Bone Miner Metab. 2013;31(4):367-80. https://doi.org/10.1007/s00774013-0444-y

4. Taguchi A. Triage screening for osteoporosis in dental clinics using panoramic radiographs. Oral diseases. 2010;16(4):316-27. https://doi org/10.1111/j.1601-0825.2009.01615.x

5. Klop C, van Staa TP, Cooper C, Harvey NC, de Vries F. The epidemiology of mortality after fracture in England: variation by age, sex, time, geographic location, and ethnicity. Osteoporos Int. 2016;28(1)(28(1)):161-8

6. Choi YJ. Dual-Energy X-Ray Absorptiometry: Beyond Bone Mineral Density Determination. Endocrinol Metab (Seoul). 2016;31(1):25-30. https://doi. org/10.3803/EnM.2016.31.1.25

7. Kanis JA, Johnell O. Requirements for DXA for the management of osteoporosis in Europe. Osteoporos Int. 2005:16(3):229-38. https://doi. org/10.1007/s00198-004-1811-2

8. Yamada S, Uchida K, Iwamoto Y, Sugino N, Yoshinari N, Kagami H, et al. Panoramic radiography measurements, osteoporosis diagnoses and fractures in Japanese men and women. Oral diseases. 2015;21(3):335-41. https://doi.org/10.1111/odi.12282

9. Panneman MJ, Lips P, Sen SS, Herings RM. Undertreatment with antiosteoporotic drugs after hospitalization for fracture. Osteoporos Int 2004;15(2):120-4. https://doi.org/10.1007/s00198-003-1544-7

10. Briançon D, de Gaudemar JB, Forestier R. Management of osteoporosis in women with peripheral osteoporotic fractures after 50 years of age: a study of practices. Joint Bone Spine. 2004;71(2):128-30. https://doi. org/10.1016/S1297-319X(03)00060-5

11. Gulsahi A, Yüzügüllü B, Imirzalioglu P, Genç Y. Assessment of panoramic radiomorphometric indices in Turkish patients of different age groups, gender and dental status. Dentomaxillofac Radiol. 2008;37(5):288-92 https://doi.org/10.1259/dmfr/19491030

12. Devlin $\mathrm{H}$, Whelton $\mathrm{C}$. Can mandibular bone resorption predict hip fracture in elderly women? A systematic review of diagnostic test accuracy. Gerodontology. 2015;32(3):163-8. https://doi.org/10.1111/ger.12077

13. Guo $Y$, Wang D, Wang Y, Peng X, Guo C. Imaging features of medicinerelated osteonecrosis of the jaws: comparison between panoramic radiography and computed tomography. Oral Surg Oral Med Ora Pathol Oral Radiol. 2016;122(2):e69-76. https://doi.org/10.1016/j. oooo.2016.04.007

14. Honda $E$, Inoue $T$, Domon M, Sasaki T, Uchida T. Dental radiographic signs characteristic to Hallermann-Streiff syndrome. Oral Surg Oral Med Oral Pathol. 1990;70(1):121-5. https://doi.org/10.1016/0030-4220(90) 90189-Y

15. Yasar F, Akgunlu F. The differences in panoramic mandibular indices and fractal dimension between patients with and without spinal osteoporosis. Dentomaxillofac Radiol. 2006;35(1):1-9. https://doi.org/10.1259/dmfr/ 97652136

16. Munhoz L, Cortes AR, Arita ES. Assessment of osteoporotic alterations in type 2 diabetes: a retrospective study. Dentomaxillofac Radiol. 2017;46(6):20160414. https://doi.org/10.1259/dmfr.20160414

17. Ohtsuki H, Kawakami M, Kawakami T, Takahashi K, Kirita T, Komasa Y Risk of osteoporosis in elderly individuals attending a dental clinic. Int Dent J. 2016.

18. Savic Pavicin I, Dumancic J, Jukic T, Badel T, Badanjak A. Digital orthopantomograms in osteoporosis detection: mandibular density and mandibular radiographic indices as skeletal BMD predictors. Dentomaxillofac Radiol. 2014;43(7):20130366. https://doi.org/10.1259/ dmfr.20130366
19. Valerio CS, Trindade AM, Mazzieiro ET, Amaral TP, Manzi FR. Use of digital panoramic radiography as an auxiliary means of low bone minera density detection in post-menopausal women. Dentomaxillofac Radiol. 2013;42(10):20120059. https://doi.org/10.1259/dmfr.20120059

20. Leite AF, Figueiredo PT, Guia CM, Melo NS, de Paula AP. Correlations between seven panoramic radiomorphometric indices and bone minera density in postmenopausal women. Oral Surg Oral Med Oral Patho Oral Radiol Endod. 2010:109(3):449-56. https://doi.org/10.1016/j. tripleo.2009.02.028

21. Devlin H, Karayianni K, Mitsea A, Jacobs R, Lindh $\mathrm{C}$, van der Stelt $\mathrm{P}$, et al. Diagnosing osteoporosis by using dental panoramic radiographs: the OSTEODENT project. Oral Surg Oral Med Oral Pathol Oral Radiol Endod. 2007:104(6):821-8. https://doi.org/10.1016/i.tripleo.2006.12.027

22. Lee K, Taguchi A, Ishii K, Suei Y, Fujita M, Nakamoto T, et al. Visua assessment of the mandibular cortex on panoramic radiographs to identify postmenopausal women with low bone mineral densities. Oral Surg Ora Med Oral Pathol Oral Radiol Endod. 2005;100(2):226-31. https://doi. org/10.1016/j.tripleo.2004.11.052

23. Mohajery M, Brooks SL. Oral radiographs in the detection of early signs of osteoporosis. Oral Surg Oral Med Oral Pathol. 1992;73(1):112-7. https:// doi.org/10.1016/0030-4220(92)90167-O

24. Iwamoto $Y$, Uchida K, Sugino N, Kuroiwa H, Kitamura $Y$, Udagawa N, et al. Osteoporosis, osteoporotic fractures, and carotid artery calcification detected on panoramic radiographs in Japanese men and women. Ora Surg Oral Med Oral Pathol Oral Radiol. 2016;121(6):673-80. https://doi. org/10.1016/j.0000.2016.02.006

25. Klemetti E, Kolmakov S, Kröger H. Pantomography in assessment of the osteoporosis risk group. Scand J Dent Res. 1994;102(1):68-72. https:// doi.org/10.1111/j.1600-0722.1994.tb01156.x

26. Taguchi A, Sanada M, Krall E, Nakamoto T, Ohtsuka M, Suei Y, et al Relationship between dental panoramic radiographic findings and biochemical markers of bone turnover. J Bone Miner Res. 2003;18(9) 1689-94. https://doi.org/10.1359/jbmr.2003.18.9.1689

27. Miles DA, Razzano MR. The future of digital imaging in dentistry. Dental clinics of North America. 2000;44(2):427-38, viii.

28. Mol A. Image processing tools for dental applications. Dental clinics of North America. 2000;44(2):299-318

29. Shrout MK, Hall JM, Hildebolt CE. Differentiation of periapical granulomas and radicular cysts by digital radiometric analysis. Oral surgery, oral medicine, and oral pathology. 1993;76(3):356-61. https://doi. org/10.1016/0030-4220(93)90268-9

30. Yasar F, Sener S, Yesilova E, Akgunlu F. Mandibular cortical index evaluation in masked and unmasked panoramic radiographs. Dentomaxillofac Radiol. 2009;38(2):86-91. https://doi.org/10.1259/dmfr/56808511

31. Halling A, Persson GR, Berglund J, Johansson O, Renvert S. Comparison between the Klemetti index and heel DXA BMD measurements in the diagnosis of reduced skeletal bone mineral density in the elderly. Osteoporos Int. 2005;16(8):999-1003. https://doi.org/10.1007/s00198004-1796-x

32. Alapati S, Reddy RS, Tatapudi R, Kotha R, Bodu NK, Chennoju S Identifying risk groups for osteoporosis by digital panoramic radiography. Contemporary clinical dentistry. 2015;6(Suppl 1):S253-7. https://doi. org/10.4103/0976-237X.166833

33. Taguchi A, Ohtsuka M, Nakamoto T, Naito K, Tsuda M, Kudo $Y$, et al. Identification of post-menopausal women at risk of osteoporosis by trained general dental practitioners using panoramic radiographs. Dentomaxillofac Radiol. 2007;36(3):149-54. https://doi.org/10.1259/dmfr/31116116

34. Wenzel A. Influence of computerized information technologies on image quality in dental radiographs. Tandlaegebladet. 1991;95(12): $527-9$

35. Raitz R, Correa L, Curi M, Dib L, Fenyo-Pereira M. Conventional and indirect digital radiographic interpretation of oral unilocular radiolucent lesions. Dentomaxillofac Radiol. 2006;35(3):165-9. https://doi.org/10.1259/dmfr/ 49307329

36. Kheddache S, Mansson LG, Angelhed JE, Denbratt L, Gottfridson B, Schlossman D. Digital chest radiography: should images be presented in negative or positive mode? European journal of radiology. 1991;13(2) 151-5. https://doi.org/10.1016/0720-048X(91)90098-G

37. Hintze H, Wenzel A, Andreasen FM, Swerin I. Digital subtraction radiography for assessment of simulated root resorption cavities. Performance of conventional and reverse contrast modes. Endodontics \& denta traumatology. 1992;8(4):149-54. https://doi.org/10.1111/j.1600-9657.1992. tb00234.x

38. Wenzel A, Hintze $\mathrm{H}$. Perception of image quality in direct digital radiography after application of various image treatment filters for detectability of dental disease. Dentomaxillofac Radiol. 1993;22(3):131-4. https://doi. org/10.1259/dmfr.22.3.8299831 
39. Ferreira Junior O, Damante JH, Lauris JR. Simple bone cyst versus odontogenic keratocyst: differential diagnosis by digitized panoramic radiography. Dento maxillo facial radiology. 2004;33(6):373-8. https://doi. org/10.1259/dmfr/54063729

40. Ellingsen MA, Hollender LG, Harrington GW. Radiovisiography versus conventional radiography for detection of small instruments in endodontic length determination. II. In vivo evaluation. Journal of endodontics. 1995;21(10):516-20. https://doi.org/10.1016/S0099-2399(06)80525-X

41. Borrie F, Thomson D, Mclntyre GT. Precision of measurements on conventional negative 'bones white' and inverted greyscale 'bones black' digital lateral cephalograms. European journal of orthodontics. 2012;34(1):57-61. https://doi.org/10.1093/ejo/cjq158
42. Haak R, Wicht MJ. Grey-scale reversed radiographic display in the detection of approximal caries. Journal of dentistry. 2005;33(1):65-71. https://doi.org/10.1016/i.jdent.2004.08.003

43. Buckley KM, Schaefer CM, Greene R, Agatston S, Fay J, Llewellyn HJ, et al. Detection of bullous lung disease: conventional radiography vs digital storage phosphor radiography. AJR American journal of roentgenology. 1991;156(3):467-70. https://doi.org/10.2214/ajr.156.3.1899739 